\title{
Dental injuries in paediatric mandibular fracture patients
}

\author{
Leena Kannari $^{1}$ (D) Emilia Marttila ${ }^{1} \cdot$ Hanna Thorén ${ }^{2,3} \cdot$ Johanna Snäll $^{1}$
}

Received: 23 February 2021 / Accepted: 18 April 2021 / Published online: 28 April 2021

(c) The Author(s) 2021

\begin{abstract}
Purpose Dental injuries (DIs) are associated with facial fractures, particularly mandibular fractures. As paediatric mandibular fractures have special features, we sought to clarify the occurrence and types of DIs among this patient group. We assessed how age, injury type, and fracture location affects the occurrence of DIs and thereby defined which patients are most susceptible.

Methods This retrospective study included patients $<18$ years with a recent mandibular fracture. Predictor variables were gender, age group, mechanism of injury, type of mandibular fracture, and other associated facial fracture(s). Types and locations of DIs and tooth loss due to injury were also reported.

Results DIs were detected in $34.7 \%(n=41)$ out of 118 patients. Patients with tooth injury had on average 3.5 injured teeth. A total of $16.2 \%$ of injured teeth were lost, typically at the time of the injury. Loss of at least one tooth was seen in approximately $10 \%$ of patients. Avulsion was the most common cause of tooth loss (52.2\%). Non-complicated crown fracture (50.7\%) was the most common DI type. Statistically significant associations between studied variables and DIs were not detected.

Conclusion DIs are common and often multiple in paediatric mandibular fracture patients regardless of background factors. DIs often lead to tooth loss. Prompt replantation of an avulsed tooth, early detection of DIs, and prevention of tooth loss whenever possible are important to avoid permanent tooth defects.
\end{abstract}

Keywords Dental injury $\cdot$ Paediatric patient $\cdot$ Mandibular fracture $\cdot$ Tooth loss

\section{Introduction}

The occurrence of traumatic dental injuries (DIs) in patients with facial fractures varies between 13.1 and $22.5 \%$ [1-3]. The presence of DIs is especially high in paediatric patients with facial fractures [1,3-5] and occurs in $23 \%$ [1] to $31 \%$ [4] of patients. DIs are particularly associated with mandibular fractures (39\%) [5], with a corresponding rate of $29 \%$ in the paediatric population [1]. Most (62\%) DIs occur in permanent teeth [6]. These irreversible injuries lead to permanent disadvantages throughout adolescence and adulthood.

Leena Kannari

leena.m.kannari@gmail.com

1 Department of Oral and Maxillofacial Diseases, University of Helsinki and Helsinki University Hospital, 00029 Helsinki, Finland

2 Department of Oral and Maxillofacial Surgery, Institute of Dentistry, University of Turku, Turku, Finland

3 Department of Oral and Maxillofacial Diseases, Turku University Hospital, Turku, Finland
More than half of reported DIs in patients with facial fractures are crown or root fractures [4, 5]. In addition, avulsions and luxations are fairly frequent $[2,5]$. The majority of DIs are easy to detect at the primary assessment by clinical examination and supplementary radiological imaging. However, root fractures and delayed pulp necrosis in particular require closer examination and long-term follow-up [7, 8]. The paediatric patient's lack of cooperation and the characteristics of developing dentition may also complicate the detection of DIs and thereby hinder initiation of treatment.

DIs may lead to numerous dental visits and long-term rehabilitation of occlusion. Final reconstructions with dental implants, if needed, are not recommended before the end of adolescence [9]. Thus, DIs may affect self-esteem and psychological well-being, especially in teenagers. This highlights the importance of the best possible treatment of DIs.

The purpose of this study was to evaluate the occurrence and types of DIs in mandibular fracture patients among children and adolescents. We sought to clarify how age, injury type, and fracture location affect the occurrence of DIs and how this information may identify which patients are most 
susceptible to DIs and would benefit from further assessments by dentists specialized in tooth injuries. We hypothesized that DIs are common in the present facial fracture population and routine collaboration with dentists treating paediatric injuries may be necessary.

\section{Patients and methods}

\section{Study design}

The records of all patients $<18$ years presenting at the Emergency Unit of Oral and Maxillofacial Surgery at Helsinki University Hospital with a recent mandibular fracture between 1 January 2013 and 31 December 2018 were retrieved from electronic patient records. All injury-related patient records were assessed retrospectively.

The following data were recorded from the patient files: age, sex, injury mechanism, type of mandibular fracture(s), possible associated facial fracture(s), injury-induced DIs, and duration of follow-up.

\section{Study variables}

The outcome variable was DI and was defined as any clinically or radiologically (or both) detected injury of the dentition that had been caused by the trauma leading to the mandibular fracture. DIs were detected at either the first health care contact or during the further injury follow-ups.

The predictor variables were sex, age group, mechanism of injury, type of mandibular fracture, and other associated facial fracture(s). Age was stratified into one of the following subgroups: (1) $<7$ years, (2) between 7 and 12 years, (3) between 13 and 15 years, and (4) between 16 and 17 years. Injury mechanisms were grouped into the following seven categories: (1) assault, (2) ground-level fall, (3) bicycle accident, (4) traffic accident, (5) sports accident, (6) fall from height, and (7) other (i.e. none of the previous six). Fracture(s) of the mandible were further classified as (1) tooth-bearing region fracture(s); (2) non-tooth-bearing region fractures (i.e. fracture[s] of the mandibular condyle, ramus, or both); or (3) combined fractures (i.e. combination of the previous two).

Types and locations of the DIs and tooth loss were reported. The main type of each DI was categorized as noncomplicated crown fracture, complicated fracture, avulsion, luxation, intrusion, swinging tooth (i.e. a tooth with increased mobility caused by injury), and other (i.e. none of the previous six, for example contusion leading to toothache, pulp necrosis, or both during the follow-up). In addition, the duration of the follow-up period in the hospital, hospital outpatient care, or both was reported.

\section{Statistical analyses}

Data were analysed using GraphPad Prism version 5.00 (GraphPad Inc.). The two-tailed Mann-Whitney test was used to assess the significance of the differences in continuous variables. Fisher's exact test was used to examine the association between variables with nominal scales. $p$-values $<0.05$ were considered statistically significant.

\section{Results}

Data from a total of 118 patients $<18$ years with mandibular fractures were included and analysed. Descriptive statistics of the patients are presented in Table 1. The mean age of the patients at the time of injury was 13.3 years (range 0.5-17.9, median 14.6 years). Most patients were male (72.9\%). The most common fracture mechanism was ground-level fall (23.7\%) followed by bicycle accident (22.9\%). Over half of the patients had fractures involving a non-tooth-bearing region (56.8\%). Follow-up durations in the hospital or

Table 1 Descriptive statistics of 118 patients with mandibular fracture

\begin{tabular}{lll}
\hline Age & Years & \\
Range & $0.5-17.9$ & \\
Mean & 13.3 & \\
Median & 14.6 & \\
Gender & Number of patients & \% of 118 \\
Male & 86 & 72.9 \\
Female & 32 & 27.1 \\
Age (years) & & \\
$<7$ & 15 & 12.7 \\
$\geq 7$ to $<13$ & 30 & 25.4 \\
$\geq 13$ to $<16$ & 28 & 23.7 \\
$\geq 16$ to $<18$ & 45 & 38.1 \\
Mechanism of injury & & \\
Ground-level fall & 28 & 23.7 \\
Bicycle accident & 27 & 22.9 \\
Assault & 18 & 15.3 \\
Traffic accident & 14 & 11.9 \\
Sports accident & 14 & 11.9 \\
Fall from height & 12 & 10.2 \\
Other & 5 & 4.2 \\
Mandibular fracture type & & \\
Tooth-bearing region & 16 & 13.6 \\
Non-tooth-bearing region & 67 & 56.8 \\
Combined & 35 & 29.7 \\
Mandible with other facial fracture & & \\
Yes & 13 & \\
No & 105 & \\
\hline
\end{tabular}


hospital outpatient clinic ranged from 1 week to 3 years. Most patients ( $83.1 \%$ ) were followed for a minimum of 1 month.

DIs were detected in 41 of the 118 patients $(34.7 \%)$. The total number of injured teeth was 142 . Differences between studied variables in patients with and without DIs remained statistically non-significant (Table 2). However, 23 of 41 patients with DIs $(56.1 \%)$ had fractures exclusively in the non-tooth-bearing regions, whereas only 4 out of $41(9.8 \%)$ had fractures exclusively in the tooth-bearing regions.

Overall, there were 112 injured permanent teeth and 30 injured deciduous teeth. The number of injured teeth ranged from 1 to 11 (mean 3.5). DIs were equally frequent in the lower and upper jaw, with 71 DIs in each. Non-complicated crown fracture was the most common DI type in both permanent (51.7\% of 112 permanent teeth) and deciduous teeth (42.6\% of 30 deciduous teeth), followed by complicated fracture in permanent teeth (15.2\% of 112 permanent teeth) and avulsion in deciduous teeth (33.1\% of 30 deciduous teeth). Nine patients had combinations of several types of injuries, such as crown fracture and luxation. Intruded teeth were rare and occurred in only $1.4 \%$ of the patients. Nine of the total 20 avulsed teeth were replanted during primary care.

Of all 142 tooth injuries, the majority were observed in permanent upper incisors $(17.6 \%)$, permanent lower canines $(8.5 \%)$, and permanent lower incisors $(7.7 \%)$. Of 30 injured deciduous teeth, upper incisors were injured most often (23.3\%) (Fig. 1).

Tooth loss occurred in 12 patients (10.2\%) and in 23 of 142 injured teeth $(16.2 \%)$. Of lost teeth, 13 were permanent and 10 were deciduous teeth. Most lost teeth (18 out of $23,78.3 \%$ ) were lost at time of injury or immediately after primary care. The remaining 5 teeth were lost during further follow-up (range 3 months to 3.5 years, mean 2.6 years, median 1.75 years).

Upper incisors were lost most often (Fig. 1). Reasons for tooth loss included avulsion or failed replantation of an avulsed tooth ( $n=12,52.2 \%$ out of 23 teeth lost), complicated root or crown fractures, or both $(n=5,21.7 \%$ out of 23 lost teeth) (Fig. 2), and one intrusion (4.3\% out of 23 lost teeth). The remaining 5 teeth were lost due to periodontal ligament injury, with or without pulp necrosis, and were situated in the fracture line ( $21.7 \%$ out of 23 teeth).
Table 2 Statistics of 118 patients with and without dental injury

\begin{tabular}{|c|c|c|c|c|c|c|}
\hline & $n$ & $\begin{array}{l}\text { Dental } \\
\text { injury: yes }\end{array}$ & $\%$ of $n$ & $\begin{array}{l}\text { Dental } \\
\text { injury: no }\end{array}$ & $\%$ of $n$ & \\
\hline All & 118 & 41 & 34.7 & 77 & 65.3 & \\
\hline \multicolumn{7}{|l|}{ Sex } \\
\hline Male & 86 & 29 & 33.7 & 57 & 66.3 & \multirow[t]{2}{*}{$p=0.8282$} \\
\hline Female & 32 & 12 & 37.5 & 20 & 62.5 & \\
\hline \multicolumn{7}{|l|}{ Age group } \\
\hline$<7$ & 15 & 6 & 40.0 & 9 & 60.0 & \multirow[t]{4}{*}{$p=0.7433$} \\
\hline$\geq 7$ to $<13$ & 30 & 12 & 40.0 & 18 & 60.0 & \\
\hline$\geq 13$ to $<16$ & 28 & 10 & 35.7 & 18 & 64.3 & \\
\hline$\geq 16$ to $<18$ & 45 & 13 & 28.9 & 32 & 71.1 & \\
\hline \multicolumn{7}{|l|}{ Mechanism of injury } \\
\hline Ground-level fall & 28 & 13 & 46.4 & 15 & 53.6 & \multirow[t]{7}{*}{$p=0.1862$} \\
\hline Bicycle accident & 27 & 11 & 40.7 & 16 & 59.3 & \\
\hline Assault & 18 & 2 & 11.1 & 16 & 88.9 & \\
\hline Traffic accident & 14 & 6 & 42.9 & 8 & 57.1 & \\
\hline Sports accident & 14 & 3 & 21.4 & 11 & 78.6 & \\
\hline Fall from height & 12 & 5 & 41.7 & 7 & 58.3 & \\
\hline Other & 5 & 1 & 20.0 & 4 & 80.0 & \\
\hline \multicolumn{7}{|l|}{ Mandibular fracture type } \\
\hline Tooth-bearing region & 16 & 4 & 25.0 & 12 & 75.0 & \multirow[t]{3}{*}{$p=0.5765$} \\
\hline Non-tooth-bearing region & 67 & 23 & 34.3 & 44 & 65.7 & \\
\hline Combined & 35 & 14 & 40.0 & 21 & 60.0 & \\
\hline \multicolumn{7}{|c|}{ Mandible with other facial fracture } \\
\hline Yes & 13 & 5 & 38.5 & 8 & 61.5 & \multirow[t]{2}{*}{$p=0.7652$} \\
\hline No & 105 & 36 & 34.3 & 69 & 65.7 & \\
\hline
\end{tabular}




\begin{tabular}{|c|c|}
\hline $\begin{array}{l}\text { Lost deciduous teeth } \\
\% \text { of } 30 \text { injured } \\
\text { deciduous teeth }\end{array}$ & \\
\hline upper first incisors & \\
\hline upper second incisors & 3.3 \\
\hline upper canines & \\
\hline upper first molars & 0 \\
\hline upper second molars & 3.3 \\
\hline lower first & 3.3 \\
\hline lower second incisors & 3.3 \\
\hline lower canines & 3.3 \\
\hline lower first molars & \\
\hline lower second molars & \\
\hline
\end{tabular}

Injured deciduous teeth $\%$ of 30 injured deciduous teeth
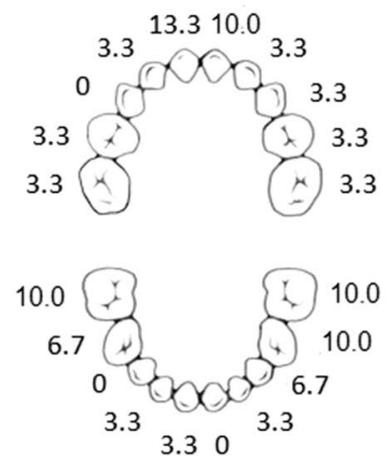

Injured permanent teeth $\%$ of 112 injured permanent teeth
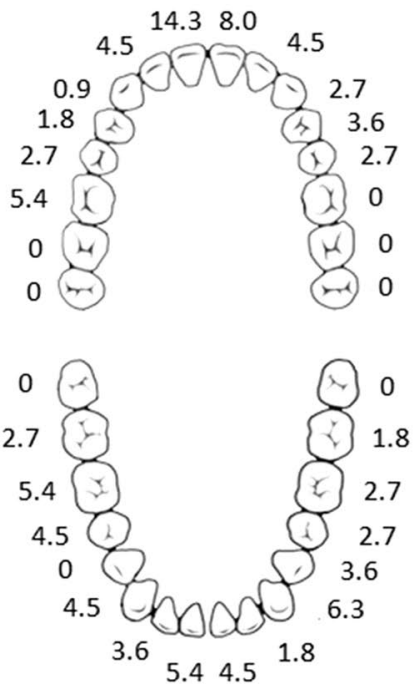

Lost permanent teeth

$\%$ of 112 injured permanent teeth

upper first incisors

3.6

upper second incisors

1.8

upper canines

1.8

upper first premolars 0

upper second premolars $\quad 0$

upper first molars 0

upper second molars 0

upper wisdom teeth 0

lower first incisors $\quad 1.8$

lower second incisors 0

lower canines $\quad 0.9$

lower first premolars $\quad 0.9$

lower second premolars 0

lower first molars $\quad 0.9$

lower second molars $\quad 0$

lower wisdom teeth 0

Fig. 1 Locations of injured and lost teeth in children and adolescents with mandibular fractures

\section{Discussion}

The purpose of this study was to evaluate the occurrence and types of DIs in paediatric patients with mandibular fracture. We hypothesized that DIs are common in these patients and routine collaboration with dentists treating paediatric injuries may be necessary. Our hypothesis was confirmed. DIs were common regardless of background factors and occurred in more than a third $(34.7 \%)$ of the patients. Up to $16 \%$ of damaged teeth were lost and most of these (78.3\%) were lost at the primary injury stage. DIs were often multiple and one or more teeth were lost in every tenth patient.

Traumatic tooth loss was usually seen in the upper incisive region. The number of avulsed teeth was also rather high; $52.2 \%$ of lost teeth were due to avulsion, failed replantation of an avulsed tooth, or both. However, it should be

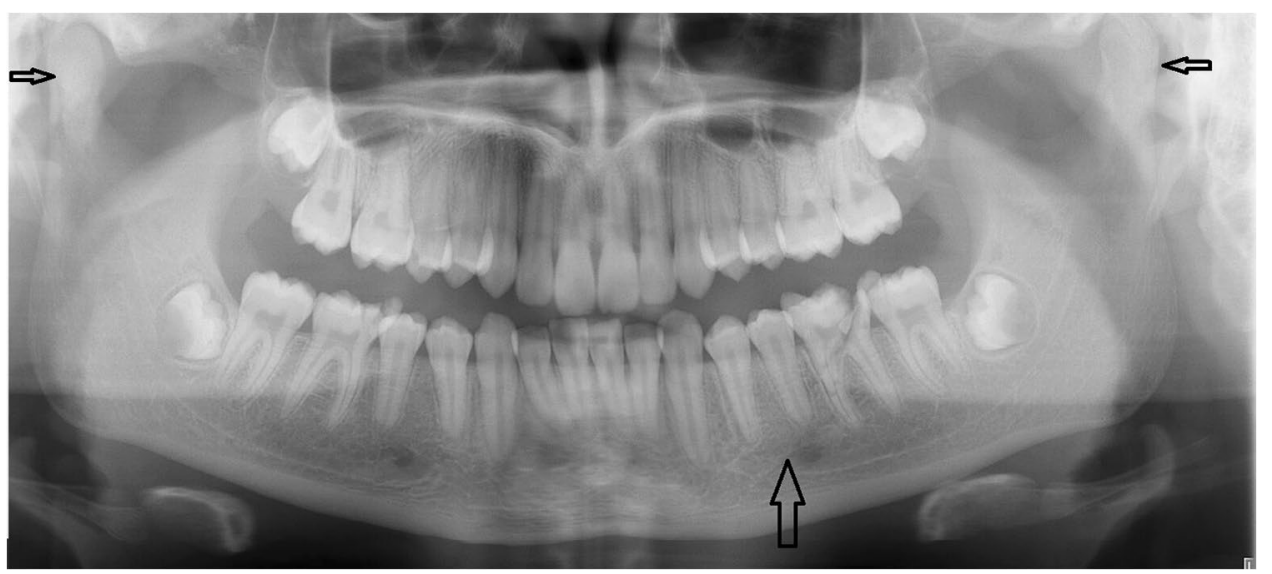

Fig. 2 A 14-year-old girl suffered bilateral condylar fractures with an additional symphysis fracture of the mandible and multiple dental injuries due to fainting and ground-level fall. A dental panoramic radiograph image shows a sagittal corpus fracture (wide arrow) and bilateral condyle fractures (small arrows) of the mandible, which were more detectable with additional imaging. Fractures were treated by intermaxillary fixation and a soft diet. A fragmentary crown-root fracture was observed in the lower left first molar that was removed under general anaesthesia at primary fracture treatment. Additionally, crown fractures were observed in the upper right second premolar and lower right first molar. The lower left premolars did not respond to vitalometer after injury, which was partially explained by the fracture-related neurosensory disturbance in mandibular inferior nerve. Further dental follow-up revealed periapical signs of devitalization and the patient received root treatment to the lower second premolar 14 months after injury. Tooth loss was replaced with an implant at the end of the patient's growth 
noted that only $22 \%$ of the replanted teeth were lost during the follow-up. Thus, early immediate replantation of a permanent tooth may result in successful or at least longterm benefit. Sometimes, the consequences of dental accidents must be treated after years or even decades. Although replacement of lost teeth for appearance would be important, dental implant reconstruction is not recommended until the end of growth. Premature implantation can lead to complications, such as infraocclusion and rotation of dental implants [9]. Therefore, the importance of early replanting should be emphasized in paediatric patients. As it is known that teeth have a considerable effect on appearance [10,11], these injuries may affect patients in different ways throughout their childhood and teenage years.

Patients with combined mandibular and other facial fractures suffered from DIs more frequently than patients with an isolated mandibular fracture. Injuries causing multiple facial fractures are often due to high-energy trauma. However, although not statistically significant, a notable finding was that over half $(56.1 \%)$ of the patients who had DIs had fractures only in the ascending part of the mandible, indicating that DIs frequently occur indirectly as a result of forceful closure of the lower jaw. Surprisingly, DIs were infrequently associated with fractures in tooth-bearing areas. On the other hand, teeth in the fracture line are prone to pulp or ligament injuries (or both), which may occur with a delay [12] and be asymptomatic [13]. Therefore, teeth in the fracture line in particular should be followed from months to years [14].

The rate of DIs in this study is consistent with previous studies [1, 3, 5, 15]. Although Lieger et al. observed the highest rates in adolescents [5], in the present study with a larger number of patients, DIs were more prevalent in younger age groups, although no statistical significance was observed. The changing proportions of the facial regions during growth may explain the prevalence of DIs in younger age groups. The lower jaw and teeth form a significant part of the face in children, whereas the midfacial region and sinuses grow to a greater proportion of the face with increasing age. Additionally, motor skills are still developing and facial protection at time of injury may be deficient even though playing, climbing, and all forms of movement are integral parts of daily life. Primary teeth are also a slightly softer than permanent teeth $[16,17]$ and are thus more prone to fractures. Overall, in the mandibular fracture population, the youngest children were more prone to DIs than older age groups for several reasons.

Even if non-complicated crown fracture was the most common DI type in this study, consistent with previous studies [1, 5], DIs were often multiple. Further DI treatment may require numerous visits and general anaesthesia may be required for children. Additionally, neurosensory disturbances may create challenges in endodontic diagnosis. Regular comprehensive clinical examinations combined with radiological evaluations are often required, for up to 5 years after injury depending on the tooth injury $[7,13,14]$.

Limitations of this study include the retrospective nature and range of the follow-up period. Long-term outcomes are thus underrepresented in studies focusing on fractures. Therefore, DI occurrence in the present study is probably underestimated due to the varying follow-up periods in our unit.

\section{Conclusions}

The present study highlights the frequency and severity of DIs in paediatric and adolescent patients with mandibular fractures. DI patients had an average of 3.5 injured teeth. In $29.3 \%$ of DI patients, the injury resulted in tooth loss, which typically occurred at the time of injury or during the immediate treatment of the fracture. Thus, DIs are not only common but are also often severe and lead to tooth loss. Prompt replantation of avulsed teeth as soon as possible, preferably in less than an hour [18], as well as early careful dental evaluation, and systematic practices for further follow-up can be recommended for all paediatric patients with mandibular fractures.

Funding Open access funding provided by University of Helsinki including Helsinki University Central Hospital. Authors L.K., E.M., and J.S. were funded by Helsinki University Hospital Fund.

Data availability Data are available on request.

Code availability Not applicable.

\section{Declarations}

Ethics approval The internal board of the Head and Neck Center of the Helsinki University Hospital, Helsinki, Finland, approved the study protocol (HUS/356/2017).

Consent to participate Not applicable.

Consent for publication Not applicable.

Competing interests The authors declare no competing interests.

Open Access This article is licensed under a Creative Commons Attribution 4.0 International License, which permits use, sharing, adaptation, distribution and reproduction in any medium or format, as long as you give appropriate credit to the original author(s) and the source, provide a link to the Creative Commons licence, and indicate if changes were made. The images or other third party material in this article are included in the article's Creative Commons licence, unless indicated otherwise in a credit line to the material. If material is not included in the article's Creative Commons licence and your intended use is not permitted by statutory regulation or exceeds the permitted use, you will need to obtain permission directly from the copyright holder. To view a copy of this licence, visit http://creativecommons.org/licenses/by/4.0/. 


\section{References}

1. Iso-Kungas $P$, Törnwall J, Suominen AL, Lindqvist C, Thorén $H$ (2012) Dental injuries in pediatric patients with facial fractures are frequent and severe. J Oral Maxillofac Surg 70(2):396-400

2. Roccia F, Boffano P, Bianchi FA, Ramieri G (2013) An 11-year review of dental injuries associated with maxillofacial fractures in Turin Italy. Oral Maxillofac Surg 17(4):269-274

3. Thorén H, Numminen L, Snäll J, Kormi E, Lindqvist C, lizuka T, Törnwall J (2010) Occurrence and types of dental injuries among patients with maxillofacial fractures. Int J Oral Maxillofac Surg 39(8):774-778

4. Gupta M, Das D, Soodan K, Singh C (2019) Dental injuries in patients associated with fracture of facial bones. Oral Maxillofac Surg 23:63-69

5. Lieger O, Zix J, Kruse A, Iizuka T (2009) Dental injuries in association with facial fractures. J Oral Maxillofac Surg 67(8):1680-1684

6. Hall E, Hickey P, Nguyen-Tran T, Louie J (2016) Dental trauma in a pediatric emergency department referral center. Pediatr Emerg Care 32(12):823-826

7. Abbott PV (2019) Diagnosis and management of transverse root fractures. Dent Traumatol 35(6):333-347

8. Andreasen JO, Andreasen FM, Mejàre I, Cvek M (2004) Healing of 400 intra-alveolar root fractures. 1. Effect of pre-injury and injury factors such as sex, age, stage of root development, fracture type, location of fracture and severity of dislocation. Dent Traumatol 20(4):192-202

9. Bohner L, Hanisch M, Kleinheinz J, Jung S (2019) Dental implants in growing patients: a systematic review. Br J Oral Maxillofac Surg 57(5):397-406

10. Gomes MC, Perazzo MF, Neves ÉT, Martins CC, Paiva SM (2017) Granville-Garcia AF. Oral problems and self-confidence in preschool children. Braz Dent J 28(4):523-530

11. Goyal N, Singh S, Mathur A, Makkar DK, Aggarwal VP, Sharma A, Kaur P (2017) Traumatic dental injuries prevalence and their impact on self-esteem among adolescents in India: a comparative study. J Clin Diagn Res 11(8):ZC106-ZC110
12. Snäll J, Kormi E, Lindqvist C, Suominen AL, Koivusalo AM, Törnwall J, Thorén H (2015) Pulp necrosis of teeth retained at the mandibular fracture site and the effect of dexamethasone on its occurrence. Dent Traumatol 31(2):136-139

13. Flores MT, Andersson L, Andreasen JO, Bakland LK, Malmgren B, Barnett F, Bourguignon C, DiAngelis A, Hicks L, Sigurdsson A, Trope M, Tsukiboshi M, von Arx T, International Association of Dental Traumatology (2007) Guidelines for the management of traumatic dental injuries. I. Fractures and luxations of permanent teeth. Dent Traumatol 23(2):66-71

14. Chrcanovic BR (2014) Teeth in the line of mandibular fractures. Oral Maxillofac Surg 18(1):7-24

15. Rahimi-Nedjat RK, Sagheb K, Walter C (2014) Concomitant dental injuries in maxillofacial fractures - a retrospective analysis of 1219 patients. Dent Traumatol 30(6):435-441

16. Correr GM, Alonso RC, Consani S, Puppin-Rontani RM, Ferracane JL (2007) In vitro wear of primary and permanent enamel. Simultaneous erosion and abrasion. Am J Dent 20(6):394-399

17. Ijbara M, Wada K, Tabata MJ, Wada J, Inoue G, Miyashin M (2018) Enamel microcracks induced by simulated occlusal wear in mature, immature, and deciduous teeth. Biomed Res Int 16(2018):5658393

18. Andersson L, Andreasen JO, Day P, Heithersay G, Trope M, Diangelis AJ, Kenny DJ, Sigurdsson A, Bourguignon C, Flores MT, Hicks ML, Lenzi AR, Malmgren B, Moule AJ, Tsukiboshi M (2012) International association of dental traumatology guidelines for the management of traumatic dental injuries: 2 Avulsion of permanent teeth. Dent Traumatol 28(2):88-96

Publisher's Note Springer Nature remains neutral with regard to jurisdictional claims in published maps and institutional affiliations. 